\title{
The acute Toxicological effects of Gammalin 20 on the lung and Pancreas of Guinea Pig
}

\author{
${ }^{*}$ DEDE, E $\mathbf{B}^{1}$; DOGARA, F $\mathbf{M}^{2}$ \\ ${ }^{1}$ Department of Pharmacology and Toxicology, College of Health Sciences, University of Port Harcourt, Choba, Port Harcourt, Rivers \\ State, Nigeria. \\ ${ }^{2}$ Department of Human Anatomy, College of Health Sciences, University of Port Harcourt, Choba, Port Harcourt, Rivers State, Nigeria.
}

\begin{abstract}
The acute toxicological effects of Gammalin 20 (gamma Isomer of hexachlorocyclohexane) on the lungs and Pancreas of Guinea Pig were investigated. Twenty-Eight Guinea Pigs of 300gm average body wt were used for the study. Five dose levels $0.0 \mathrm{gkg}$., $0.82 \mathrm{gkg}^{-1}$., $1.63 \mathrm{gkg}^{-1} ., 3.25 \mathrm{gkg}^{-1}$ and $6.5 \mathrm{gkg}^{-1}$ were obtained after a range finding test using five guinea pigs and administered intra peritoneally, into the animals. Signs and symptoms of toxicity (Irritability, staggering, laboured breathing, convulsion and death) were observed, scored in this order of severity and found to be dose dependent. Histopathological examination of the lungs revealed edema, congestion and disruption of lung architecture. The Pancreas showed acute toxic inflammatory reaction, edema, acute pancreatitis and disruption of Pancreatic architecture. $\mathrm{LD}_{50}$ of gammalin 20 in the male guinea pig using intraperitoneal route was $1.87 \mathrm{gkg}-1$. gammalin 20 therefore based on classification of toxicity of chemicals was found to be slightly toxic to the male guinea pig using intraperitoneal route of administration. @JASEM
\end{abstract}

The use of chemicals as insecticides had been reported (Hassal,1987). Furthermore, Beat, 1970, a report on human toxicosis resulting from Pesticide use,. defined the term Pesticides as insecticides, herbicides, fungicides and rodenticides Reports (Dede and Chike 2000, on chronic effects of dichlorvos on the rat liver., Iyaniwaura et al 1991a, on management of acute coumaphos poisoning in mice.,, Iyaniwura et al (1991b on Mammalian toxicity of Coumaphos and its interaction with Aldrin in mice) indicated toxicity of chemicals (pesticides) on non-target tissues. However, no reports have so far been presented on the toxicity of gammalin 20 on Guinea Pig tissues.

The lung is known to be an organ of respiration. They affect aeration of blood. Xenobiotics including chemicals can adversely affect the lungs resulting, in such conditions as respiratory insufficiency (Guyton, 1976). On the other hand the Pancreas is a large elongated racemose gland situated transversely behind the stomach, between the spleen and duodenum. The external secretion contains digestive enzymes while internal secretions include glucagon and insulin, which are produced by the alpha and beta cells respectively. The alpha and Beta cells form an aggregate often referred to as Islet of Langerhans (Dorland, 1977).

The current study therefore is aimed at investigating the possible effects of gammalin 20

\section{RESULTS AND DISCUSSION}

Median lethal dose (LD50) Determination): The $\mathrm{LD}_{50}$ value for gammalin 20 (Isomer hexachlorocyclohexane) in Guinea Pigs using

*Corresponding author: E-mail:

Abstracts available Online at http://www.ajol.info (gamma Isomer of hexachlorocyclohexane) on these very important organs, the lung and Pancreatic tissues of male Guinea pig.

\section{MATERIALS AND METHOD}

Thirty male guinea pigs of $300 \mathrm{~g}$ average body weights were used in the current study. They were incubated in wooden cages comprising five guinea pigs per group, while five were used for the pilot study. The animals were left for fourteen days as incubation period (acclimatization). Prior to commencement of the study.

Determination of $L D_{50}$. A pilot study was carried out with 5 male guinea pigs to determine the minimum dose of gammalin 20 that caused $100 \%$ death of the animals. The number of animals that died in each group were noted. $\mathrm{LD}_{50}$ was later calculated using Arithmetic method of karber (adapted by Alui and Nwude, 1982).

Histopathological study: The lungs and Pancreas of the animals in the various groups were quickly obtained after the animals were sacrificed, and fixed in 10\% formaldehyde (Dede, 1992). The various slides based on the dose ranges were studied and tissues compared with control $(0.9 \%$ saline injected guinea pigs).

intrapentoneal route of administration was calculated using Arithmetic method of Karber (adapted by Aliu and Nwude, 1982). 
Table 1 Signs and symptoms of Lindane toxicity

\begin{tabular}{ccccccc}
\hline Group & Dose $\left(\mathrm{gkg}^{-1}\right)$ & $\begin{array}{c}\text { Dose difference } \\
\left(\mathrm{g} \mathrm{kg}^{-1}\right)\end{array}$ & $\begin{array}{c}\text { No. } \\
\text { Dead }\end{array}$ & $\begin{array}{c}\text { No. of } \\
\text { Animal per group. }\end{array}$ & $\begin{array}{c}\text { Mean } \\
\text { Dead }\end{array}$ & $\begin{array}{c}\text { Dose diff } \mathrm{x} \\
\text { mean Dead }\end{array}$ \\
\hline 1 & $\begin{array}{c}0.9 \% \text { saline } \\
\text { CONTROL }\end{array}$ & - & 0 & 5 & 0 & 0 \\
2 & 0.82 & 0.82 & 2 & 5 & & \\
3 & 1.63 & 0.81 & 3 & 5 & 2.0 & 0.82 \\
4 & 3.25 & 1.62 & 4 & 5 & 3.5 & 5.63 \\
5 & 6.50 & 3.25 & 5 & 5 & 4.5 & 14.63 \\
\hline
\end{tabular}

Table 2. Signs and symptoms of Lindane toxicity on Guinea Pig score based on the order of severity.

\begin{tabular}{crlc}
\hline Groups & $\begin{array}{c}\text { Dose } \\
\left(\mathrm{gkg}^{-1}\right)\end{array}$ & \multicolumn{1}{c}{ Signs \& symptoms } & $\begin{array}{c}\text { Maximum } \\
\text { score }\end{array}$ \\
\hline 1 & $\mathrm{O}$ & Normal & 0 \\
2 & 0.82 & Irritability (4) Tremor (4) & Laboured breathing (2)Staggering (2)Convulsion (2)Death (2) \\
& & & 48 \\
3 & 1.63 & Irritability (4)Tremor (4)Laboured breathing (4)Staggering (4)Convulsion (3)Death (3) & 73 \\
4 & 3.2 & Irritability (5)Tremor (5)Laboured breathing (5)Staggering (5)Convulsion (4)Death (4) & 94 \\
5 & 6.5 & Irritability (5)Tremor (5)Laboured breathing (5)Staggering (5)Convulsion (5) Death (5) & 105 \\
& & & \\
\hline
\end{tabular}

The physical reaction of the test animals (guinea pigs) to I.P administration of Lindane indicated toxicity. The $\mathrm{LD}_{50}$ of $1.87 \mathrm{gkg}^{-1}$ was the median lethal dose of Lindane. However considering the classification of toxicity of substances Matsumura (1975).Extremely toxic substances had $\mathrm{LD}_{50}$ less than lmgkg $^{-1}$ or $=1 \mathrm{mgkg}^{-1}$ mgkg Highly toxic substances 1-50mgkg 1 , Moderately toxic substance 50$50 \mathrm{mgkg}^{-1}$. Relatively harmless $15 \mathrm{gkg}^{-1}$ and above Based on this classification, Gammalin 20 appeared slightly toxic in the male guinea pigs, using intraperitoneal route of administration. The neurological signs were an initial calmness followed by irritability, tremor and convulsion. These symptoms were indicative of the toxicity of Lindane acting on the central nervous system (Dede, 1992). The prominence of convulsion as a neurological sign in the current study was in agreement with the reports of Matsumura (1975), Smith (1991), and Dede (1992) and in which all the experimental animals exhibited convulsion as a common neurological sign of toxicity due to Lindane.

Lindane is an organo chlorine pesticide of the Hexachlorocyclohexane (HCH) sub group (Hassal, 1987). The three sub groups of Organo chlorine compounds are all neurotoxins (Iyaniwara, 1990., Matsumura 1975 and Hassal,1987). These compounds have been reported to cause destabilization of neuronal activity, resulting in hyper excitability of nerves (Hassal, 1987). The increasing rate of convulsion at high doses corresponded with the repetitive firing of action potentials at the doses $3.25 \mathrm{gkg}-1$, to $6.5 \mathrm{gkg}-5$. The repeated intense and prolonged convulsions, at higher doses might have been responsible for the increased number of death, at those doses; $3.25 \mathrm{gkg}-1$ to $6.5 \mathrm{gkg}-1$. The increased respiratory rate could be a direct result of lung reaction to Lindane (Spencer, 1977) or the effect of chemical on the respiratory centre in the reticular formation (Dede, 2001). The histopathological examination of the lungs of guinea pigs in this experiment suggested a dose dependent spectrum of toxicity to Lindane. At lower dose the classical signs of inflammatory reactions; fluid and cellular exudation with congestion of the lungs, and distention of the alveolar spaces were observed (Ramzi et al 1999). The inflammatory reactions were dose dependent. At 3.25gkg-1, there was massive consolidation of whole lobules with an increased number of inflammatory cells seen on the plates as dark specks. Vascular permeability as seen in inflammatory reactions accounted for the edema and cellular exudation. The infiltrates mainly lymphocytes and occasional plasma cells agreed with the report of Ramzi et al (1999). Acute reaction to lindane, was reported to result in lung edema (Smith, 1991). The presence of edema in this study corroborated that report by Smith, 1991. Although no histopathological report existed in the literature, on the effect of Lindane on the lungs, there were indications that Lindane is a tumour promoter in the lungs (Gandli, 1998). In the current study the guinea pigs were exposed to high lethal doses that disrupted the alveolar architecture doses $\left(3.25 \mathrm{gkg}^{-1}\right.$ to $6.5 \mathrm{gkg}^{-1}$ Lindane). Normally in inflammatory reactions of the magnitude, obtained in the current 
work, there were considerable numbers of red cells, the haemolysis of which could be responsible for the rusty coloured fluid found at the lung base on examination.

In the pancreas, the observation changes were indicative of mild interstitial edema and congestion, in the animals injected with he Gammalin 20, at doses $1.6 \mathrm{gkg}-1$ and $3.25 \mathrm{gkg}^{-1}$. This was more marked at the dose $6.5 \mathrm{gkg}^{-1}$ (plate 6) where the congestion was such that no distinct pancreatic architecture could be noticed. The interstitial edema and tissue disruption could be due to increased capillary permeability as was the usual effect of toxic substance on tissues (Guxton, 1976), or decreased plasma production due to lindane administration (Matsumura, 1995). Ischaemic injuries to the tissues, resulting from edema which compromised blood flow, often led to rupture of lysosomes and local release of activated enzymes, in acinar cells (Ramzi, 1999). This was suspected to be the main cause of acute pancreatitis observed in the current study.

Based on the results obtained from the current study it was obvious that gammalin 20 the gamma isomer of hexachlorocyclohexane had deleterious effects on both the pancreas and lung of the guinea pig. The degree of damage was dose dependent. The damage was such that could no doubt impact negatively on the physiological functions of these organs.

\section{REFERENCES}

Alui, Y.O., Nwude, N (1982) Determination of the medin lethal dose $\left(\mathrm{LD}_{50}\right)$ In: Velerenary Pharmacology \& Toxicology Experiments. Baraka Press Zaria Pp 104-122.

Beat, N.B (1970) Human toxicis resulting from pesticide use. J. of American Vet Med. Association. 157: No 11 (1835-1840)

Dede E.B. (1992) Effect of Lindane Pretreatment on dichlorvos toxicity invitro, invivo Ph.D thesis, ABU Zaria.

Dede E.B. Simini alayi (2001) Electroencephalographic study of the interaction between dichlorvos and Lindane in the Rat Brain. Nig. J. Neur. Vol. 4, 21-26.
Dede E.B., Chike, C.P.R. (2000) Histopathological study of chronic effects of dichorvos on the rat liver and small intestine J. Appl. Sci: \& Environ. Mgt. 4: 33-36.

Dorland's (1977) Dorland Pocket Medical dictionary W.B. Saunder, London PP. 510.

Guyton C.A. (1976). Textbook of Medical physiology $8^{\text {th }}$ Edition pg. 506-521.

Gandhi R. (1998) Breast Cancer Risk, An Evolution of Lindane Journal of the Programme on breast Cancer and Environmental risk factors. New York. Pg. 1-3

Hassal, H.A., (1987) Chemistry of Pesticides metabolism, mode of action and crop protection Menilluim Pg. 149-156.

Iyaniwura, T.T., Salawu, O.A., Shaba., S \& Dede E.B. (1991a) management of Acute Cumaphos poisoning in Mice. Nig J Neur. No:21-28.

Iyaniwu ra, T.T., Salawu, O.A., Shaba., S \& Dede E.B. (1991b) Mammalian toxicity of cumaphos and its interaction with Aldin in Mice Nig J., Neu. No 1 : 97-106.

Matsumura, F. (1975) Toxicology of Insecticides $2^{\text {nd }}$ Edition Plenum Press N.Y. 1995 Pg. 4-6.

Ramzi S.C., Vinay K, Collin T. (1999) Pulmonary Infections and Pancreatitis Robbins pathologic basis for disease $6^{\text {th }}$ Edition Pg 909., $717-722$.

Smith A.G., (1991). Handbook of Pesticides Toxicology Hayes W.J.Jr. Eds Academic Press Inc. New York. Pg. 3-6. 